\title{
A rare cause of diminished vision: large spheno-ethmoidal mucocele
}

\author{
T. Adouly*, C. Adnane, FZ Loufad, R Mahdoufi. Rouadi, R. Abada, M. Roubal and M. Mahtar \\ Department of ENT, 20 août hospital, Ibn Rochd university hospital, Casablanca, Morocco
}

\begin{abstract}
Sphenoid sinus mucocele comprises only $2 \%$ of all paranasal sinus mucoceles which can compress on the optic canal or inferior orbital fissure, and causing loss of vision. One case with sphenoidal sinus mucocele is reported and discussed. A 45 years-old male was complaining of decrease in vision in the right eye and severe headache at the right-sided. Computed tomography showed a right sphenoidal sinus mucocele with right ethmoidal extension and compressing the right inferior orbital fissure and the right optic nerve. The lesion was removed through an endonasale sphenoidotomy. Histological examination confirmed diagnosis. The patient's follow-up for the last six months was normal with normal vision. The rarity of sphenoidal sinus mucocele made our case interesting to report.
\end{abstract}

\section{Introduction}

Mucoceles are benign, encapsulated, locally invasive masses within a paranasal sinus, filled with mucus and lined by respiratory epithelium. However, the sphenoid sinus is the least common site of the paranasal sinuses, representing 1-2\% [1]. The presenting symptoms are primarily caused by compression on contiguous neurological and vascular structures [2]. Diminished vision is a common presenting symptom. The authors report a case of a large sphenoid sinus mucocele associated with ophthalmic symptomatology and head ache in order to describe the presenting symptoms, location, and management of this rare disease.

\section{Case history}

A 45-year-old male, presented with gradual decrease in vision in the right eye and severe headache also at the right-sided for the past six months. There were no associated nasal symptoms. The patient denied any history of paranasal sinus disease or trauma. Rhinological examination, indicated congestion on the right side but nothing else of note. Nasal endoscopic examination found no nasal polyposis or mass. Ophthalmic examination revealed a decrease of visual acuity in the right eye (7/10) and (10/10) in the left. Eye movements were normal. The neurological examination and the cranial nerves and peripheral nervous system examination was otherwise normal. A systemic examination was unremarkable. Computed tomography (CT) of the head revealed a large, well-defined lobulated mass, measuring $67 \mathrm{~mm}$ $\times 42 \mathrm{~mm} \times 32 \mathrm{~mm}$ arising from sphenoid sinus with extension into the right ethmoidal and compressing the right inferior orbital fissure and the right optic nerve. It was responsible of marked thinning of the internal wall of the orbit without erosion of the bony. There was no evidence of calcification or any fat density within the lesion. The diagnosis of a large sphenoethmoidal mucocele was suspected (Figure 1 and 2). The patient underwent an endoscopic right sphenoidotomy and drainage of the mucocele. The postoperative course was uncomplicated (no bleeding or cerebrospinal fluid leakage). Histopathology was suggestive of mucocele lined with pseudo stratified columnar epithelium. The man's vision gradually improved after operation. The patient was still free of symptoms with normal vision after six months.

\section{Discussion}

Introduction: In 1872, Rouge identified the first case of sphenoid sinus mucocele and later described by Berg in 1889 [2]. Mucoceles are benign lesions, expansile and locally destructive, causing erosions of the bony walls of the sinus [3]. Approximately two-thirds of all mucoceles are commonly found in the frontal sinuses, and the majority of the remainder involves the ethmoidal sinus $[4,5]$. The aetiology of sphenoid sinus mucocele is still unknown. Proposed theories for development of mucocele include cystic dilatation of the glandular structures and cystic development of embryonic epithelial residues [6,7]. Furthermore, Trauma and chronic inflammation (polypoid sinusitis) are considered to be causes of mucocele formation [8,9]. In the literature, some authors

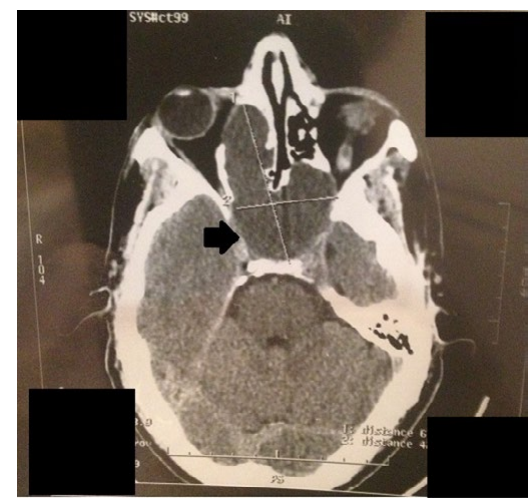

Figure 1. Axial CT revealed a large mass in sphenoid sinus with extension into the right ethmoidal with marked thinning of the internal wall of the orbit.

Correspondence to: Dr. Taoufik Adouly, resident, Department of ENT, 20 août hospital, Ibn Rochd university hospital, Casablanca, Morocco, Phone: +21265826291; E-mail: adouly.taoufik@gmail.com

Key words: sphenoid sinus, mucocele, optic nerve, headache, surgery

Received: May 16, 2016; Accepted: June 09, 2016; Published: June 13, 2016 


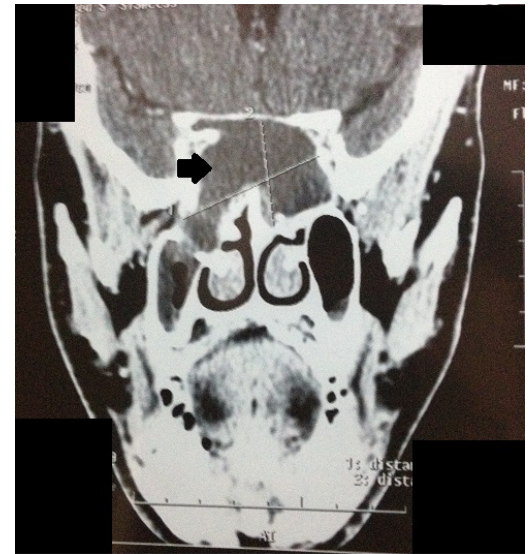

Figure 2. Coronal CT revealed a large mass in sphenoid sinus.

suggested also that late complication of radiotherapy to the head and neck can causes sphenoid sinus mucocele formation by scarred mucosa which occludes the sinus ostium [10]. Our patient didn't have any risk factor for the development of a mucocele.

Manifestation: The clinical manifestation of sphenoid sinus mucocele is dependent on to the sinus anatomy and its contiguous neurological and vascular structures such as: cranial nerves II-IIIIV-V-VI, the cavernous sinus, the carotid artery, the pituitary gland [2]. Based on literature, the clinical manifestations are variable and related to the direction of extension towards neighboring structures. The most common clinical symptom is headache which is present in $70-80 \%$ of cases. This is typically retro-orbital $[11,12]$. It can be caused by mechanical pressure on the sinus anatomy; stretching of the dura covering the planum sphenoidale and the floorof the anterior cranial fossa or by cytokines and their role in modulation of the pain threshold, and also in trigeminal sensitization [13,14]. Visual disturbance is the second commonest group of symptoms making surgery necessary. The optic nerve is the most frequently involved cranial nerve with reduction in visual acuity. Palsies of eye movement with diplopia occur in $30-50 \%$ of cases. The oculomotor nerve is affected more frequently than the trochlear and abducens nerve. Oculomotor nerve involvement accounted for $70 \%$ of ocular palsies [7, 12,15].

Diagnosis: Computed tomography $(\mathrm{CT})$ and Magnetic resonance imaging (MRI) are the imaging techniques of choice. Mucocele appears like a hypodensen on enhancing mass that fills and distorts the sinus cavity on CT, and with a low signal on T1-weighted MRI and a high signal on T2-weighted MRI due to their high water content [16]. Usually, there is no enhancement, or at most marginal enhancement on CT or MRI (T1).The differential diagnosis includes pituitary tumour, craniopharyngioma, epidermoid, chordoma, dermoid, aneurysm, metastatic lesions and arachnoid cyst $[17,18]$.

Management: The recommended management of a mucocele of the sphenoid sinus is endonasale sphenoidotomy withdrainage and marsupialization of the mucocele [19]. After six months, our patient reported an improvement in symptoms post-operatively, and showed no recurrence. It's very interestingly, the vision of the case returned to normal 6 months after surgery.

\section{Conclusion}

Sphenoid sinus mucocele is a rare entity. Imaging is crucial to diagnosis. Endoscopic drainage is safe and effective in eradication of disease. The rarity of sphenoidal sinus mucocele made our case interesting to report.

\section{Conflicts of interest}

The authors declare no conflicts of interest.

\section{References}

1. Kösling S, Hintner M, Brandt S, Schulz T, Bloching M (2004) Mucoceles of the sphenoid sinus. Eur J Radiol 51: 1-5. [Crossref]

2. Stankiewicz JA (1989) Sphenoid sinus mucocele. Arch Otolaryngol Head Neck Surg 115: 735-740. [Crossref]

3. Bockmühl U, Kratzsch B, Benda K, Draf W (2005) [Paranasal sinus mucoceles: surgica management and long term results]. Laryngorhinootologie 84: 892-898. [Crossref]

4. Levy J, Monos T, Puterman M (2005) Bilateral consecutive blindness due to sphenoid sinus mucocele with unilateral partial recovery. Can J Ophthalmol 40: 506-508. [Crossref]

5. Akan H, Cihan B, Celenk C (2004) Sphenoid sinus mucocele causing third nerve paralysis: CT and MR findings. Dentomaxillofac Radiol 33: 342-344.

6. Friedman A, Batra PS, Fakhri S, Citardi MJ, Lanza DC (2005) Isolated sphenoid sinus disease: etiology and management. Otolaryngol Head Neck Surg 133: 544-550. [Crossref]

7. Sundar U, Sharma AL, Yeolekar ME, Pahuja V (2004) Sphenoidal sinus mucocoele presenting as mono-ocular painless loss of vision. Postgrad Med J 80: 40. [Crossref]

8. Uren BA, Berkowitz RG (2003) Isolated inflammatory sphenoid sinus disease in children. Ann Otol Rhinol Laryngol 112: 370-372. [Crossref]

9. Malard O, Gayet-Delacroix M, Jegoux F, Faure A, Bordure P, et al. (2004) Spontaneous sphenoid sinus mucocele revealed by meningitis and brain abscess in a 12-year-old child. AJNR Am J Neuroradiol 25: 873-875. [Crossref]

10. Rejab E, Said H, Saim L, Thim L (1991) Sphenoid sinus mucocoele: a possible late complication of radiotherapy to the head and neck. J Laryngol Otol 105: 959-960. [Crossref]

11. Giovannetti F, Filiaci F, Ramieri V, Ungari C (2008) Isolated sphenoid sinus mucocele: etiology and management. J Craniofac Surg 19: 1381-1384. [Crossref]

12. Lee JC, Park SK, Jang DK, Han YM (2010) Isolated sphenoid sinus mucocele presenting as third nerve palsy. J Korean Neurosurg Soc 48: 360-362. [Crossref]

13. Iqbal J, Kanaan I, Ahmed M, al Homsi M (1998) Neurosurgical aspects of sphenoid sinus mucocele. Br J Neurosurg 12: 527-530. [Crossref]

14. Kariya S, Okano M, Hattori H, Sugata Y, Matsumoto R, et al. (2007) Expression of IL-12 and Thelper cell 1 cytokines in the fluid of paranasal sinus mucoceles. $\mathrm{Am} \mathrm{J}$ Otolaryngol 28: 83-86. [Crossref]

15. Levy J, Monos T, Puterman M (2005) Bilateral consecutive blindness due to sphenoid sinus mucocele with unilateral partial recovery. Can J Ophthalmol 40: 506-508. [Crossref]

16. Levine HL, Clemente MP. In: Levine HL, editor. (2004) Sinus surgery:endoscopic and microscopic approaches. New York: Thieme Medical Publishers. p.77.

17. Yokoyama T, Inoue S, Imamura J, Nagamitsu T, Jimi Y, et al. (1996) Sphenoethmoidal mucoceles with intracranial extension--three case reports. Neurol Med Chir (Tokyo) 36: 822-828. [Crossref]

18. Hejazi N, Witzmann A, Hassler W (2001) Ocular manifestations of sphenoid mucoceles: clinical features and neurosurgical management of three cases and review of the literature. Surg Neurol 56: 338-343. [Crossref]

19. Khong JJ, Malhotra R, Wormald PJ, Selva D (2004) Endoscopic sinus surgery for paranasal sinus mucocoele with orbital involvement. Eye (Lond) 18: 877-881. [Crossref]

Copyright: $(2016$ Adouly T. This is an open-access article distributed under the terms of the Creative Commons Attribution License, which permits unrestricted use, distribution, and reproduction in any medium, provided the original author and source are credited. 